\title{
Hydrothermal Synthesis and Electrochemical Properties of N- doped Activated Carbon Microspheres
}

\author{
Tingnan Yan ${ }^{1,2, \dagger}$, Jingli $X u^{1,2, \dagger}$, Zengyong Chu ${ }^{2, *}$, Enhui Liu ${ }^{1, *}$, Luo Yang ${ }^{1, *}$, Chunhua Wang ${ }^{2}$ \\ ${ }^{1}$ College of Chemistry, Xiangtan University, Xiangtan 411105, P.R. China \\ ${ }^{2}$ College of Science, National University of Defense Technology, Changsha 410073, P.R. China \\ *E-mail: chuzy@ nudt.edu.cn, liuenhui99@ sina.com.cn, yangluo@xtu.edu.cn
}

doi: $10.20964 / 2017.07 .20$

Received: 26 March 2017 / Accepted: 25 April 2017 / Published: 12 June 2017

\begin{abstract}
$\mathrm{N}$-doped carbon microspheres were fabricated from glucose using $\mathrm{g}-\mathrm{C}_{3} \mathrm{~N}_{4}$ quantum dots as the nitrogen source under hydrothermal conditions. The carbon microspheres were found remarkably enlarged from $0.4 \mu \mathrm{m}$ to $5.0 \mu \mathrm{m}$ after the addition of the quantum dots. Adjustable nitrogen content in the form of pyridinic $(\mathrm{N}-6)$ or pyrrolic or pyridone $(\mathrm{N}-5)$ was introduced into the carbon microspheres up to 6.48 $\%$. The surface areas of the activated carbon microspheres are comparable to those of the un-doped smaller ones. Electrochemical analysis indicates that nitrogen doping leads to both enhanced conductivity and enhanced specific capacitance up to $281 \mathrm{~F} / \mathrm{g}$ at $2 \mathrm{~A} / \mathrm{g}$.
\end{abstract}

Keywords: activated carbon microspheres, hydrothermal synthesis, glucose, $g-\mathrm{C}_{3} \mathrm{~N}_{4}$, specific capacitance.

\section{$\underline{\text { FULL TEXT }}$}

(C) 2017 The Authors. Published by ESG (www.electrochemsci.org). This article is an open access article distributed under the terms and conditions of the Creative Commons Attribution license (http://creativecommons.org/licenses/by/4.0/). 